\title{
EXTENSÃO UNIVERSITÁRIA EM DESIGN: EXPERIÊNCIAS DO LABORATÓRIO DE DESIGN SOLIDÁRIO JUNTO À OFICINA DE VITRAL DA ASSOCIAÇÃO CORNÉLIA VLIEG
}

\author{
Marcela Rezende Pires Rosas \\ Universidade Estadual Paulista "Júlio de Mesquita Filho", UNESP \\ marcelarezendepires@gmail.com \\ Claudio Roberto y Goya \\ Universidade Estadual Paulista "Júlio de Mesquita Filho", UNESP \\ goyaclaudio@hotmail.com \\ Bruno Müller da Silva \\ Universidade Estadual Paulista "Júlio de Mesquita Filho", UNESP \\ brn.muller@gmail.com
}

\begin{abstract}
Resumo: Este artigo é parte do projeto de iniciação científica em andamento e tem como objetivo descrever a parceria realizada entre o Laboratório de Design Solidário com a Associação Cornélia Vlieg, uma organização sem fins lucrativos que atua na reabilitação psicossocial de pessoas que sofrem de transtornos mentais através da oferta de oficinas que funcionam como espaços de trabalho contribuintes na inclusão social desses indivíduos. A associação oferece 14 oficinas diferentes e entrou em contato com o Labsol a fim de aprimorar o trabalho que já realizam. Tendo como base teórica os conceitos de Sustentabilidade, Ecodesign e Economia Solidária e os autores Singer, Vezzoli, Manzini e Baxter é possível discutir e entender a necessidade da proposta feita pelo laboratório de um redesign dos artefatos da Oficina de Vidro, compreendendo sua importância enquanto patrimônio cultural, agregando valor a sua linha de produção e prezando sua inserção no mercado.
\end{abstract}

Palavras-chave: Vidro, Artesanato, Economia Solidária, Ecodesign, Sustentabilidade.

\begin{abstract}
This article is part of a research project in progress and aims to describe the partnership held between Laboratório de Design Solidário and Associação Cornélia Vlieg, a nonprofit organization that works on psychosocial rehabilitation of people that are suffering from mental disorders by offering workshops that work as workspaces that helps in the social inclusion of these individuals. The association has 14 different workshops and contacted Labsol in order to enhance their work. Basis on the concepts of Sustainability, Ecodesign and Solidarity Economy and the authors Singer, Vezzoli, Manzini and Baxter we are able to discuss and understand the need for the proposal made by the laboratory of a redesign
\end{abstract}


of the Glass Workshop artifacts, including its importance as cultural heritage, adding value to its production line and valuing their insertion in the market.

Key-words: Glass, Handicrafts, Solidarity Economy, Ecodesign, Sustainability.

\section{INTRODUÇÃO}

Pertencente ao Departamento de Design da Instituição de Ensino, o Laboratório de Design Solidário, LabSol, trabalha com ações que promovem o desenvolvimento do trabalho artesanal de grupos e comunidades que apresentam demandas por qualificar e aprimorar suas produções, levando em consideração o design de suas peças, sua produção e comercialização.

Em atividade desde 2007, o LabSol vem desde então realizando parceria com comunidades e cooperativas de artesãos. Em 2015, o laboratório foi contatado pela Associação Cornélia Vlieg, sediada em Campinas-SP, para desenvolverem um trabalho conjunto entre artesanato e design, já que a dinâmica de trabalho do grupo é focada nos princípios de Economia Solidária, um dos pilares conceituais do laboratório junto ao Ecodesign e a Sustentabilidade.

A associação conta com o Núcleo das Oficinas, o NOT, sede das 14 oficinas que compõe a marca Armazém das Oficinas, responsável por comercializar os artefatos. Os integrantes do LabSol foram até a sede do Núcleo das Oficinas em 2015, para entender o funcionamento das oficinas e a produção artesanal do grupo. Durante os meses que já dura a parceria, foram levantadas diversas demandas e produzidos alguns protótipos que foram bem recebidos pelos artesãos. Este trabalho discorrerá sobre o desenvolvimento de produtos para oficina de vidro, especificamente, que ainda se encontra em andamento.
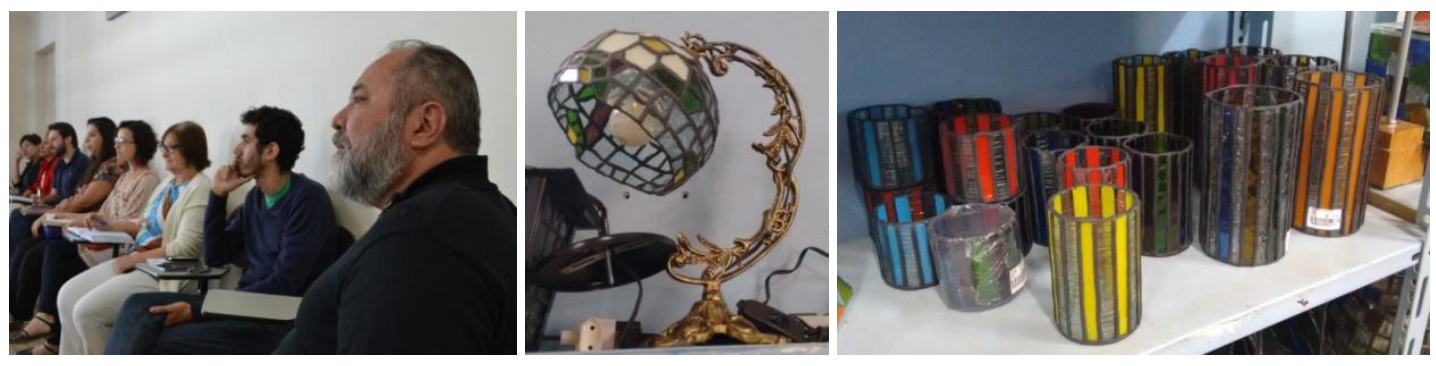

Figura 1 - Visita do LabSol ao Núcleo das Oficinas de Trabalho, Luminária e porta-trecos produzidos pela oficial de vitral.

Fonte: Acervo Labsol.

\section{DESENVOLVIMENTO}

\subsection{O Labsol}

O Labsol, Laboratório de Design Solidário, é um Projeto de Extensão vinculado ao Departamento de Design da Instituição de Ensino Superior, que tem suas ações embasadas pelos princípios e conceitos do tripé Sustentabilidade, Ecodesign e Economia Solidária. A principal missão do Labsol é desenvolver ações em parceria com comunidades e grupos que tenham como base financeira o artesanato, orientando as 
técnicas e processos produtivos, agregando valor a sua linha de produção através do design e prezando a identidade cultural, patrimônio histórico da comunidade local e sua inserção no mercado.

\subsection{0 tripé: Sustentabilidade, Ecodesign e Economia Solidária}

A Sustentabilidade faz referencia às condições sistêmicas, segundo as quais em nível regional e planetário, as atividades humanas não devem interferir nos ciclos naturais em que se baseia tudo o que a resiliência do planeta permite, e ao mesmo tempo, não devem empobrecer seu capital natural, que será transmitido ás gerações futuras (MANZINI \& VEZZOLI, 2008, p.27). Portanto, compreende-se por Sustentabilidade a capacidade de utilizar ferramentas e estratégias que conciliem as necessidades de desenvolvimento material e econômico com a preservação do meio ambiente, de forma que a biodiversidade e ecossistemas locais e planetários não sejam comprometidos.

Aliado aos princípios da sustentabilidade, o Ecodesign tem como principal objetivo desenvolver produtos, sistemas e serviços compatíveis com o uso consciente de recursos não renováveis e que sejam capazes de minimizar o impacto ambiental causado pela sua produção e ciclo de vida. Segundo MANZINI e VEZZOLI $(2008$, p.18) é "uma aptidão projetual, que concebe os aspectos do projeto, considerando também o impacto ambiental", e (p.91) "considera-se o produto desde a extração dos recursos necessários para a produção dos materiais que o compõem (nascimento) até o último tratamento (morte) desses materiais após o uso do produto".

Complementando essa mesma linha, a Economia Solidária "é uma economia de mercado com base associativista e cooperativista, voltada para a produção, consumo e comercialização de bens e serviços, buscando a valorização do ser humano e não do capital, dentro de um processo de democratização econômica" (SINGER, Paul, 2002). Trata-se de produzir através de práticas econômicas e sociais não competitivas que valorizam a autogestão, a horizontalidade e o cooperativismo, ou seja, um formato organizacional que beneficia todos os seus integrantes, pois não há relações hierárquicas ou exploração de mão de obra, resultando numa igualdade de poder de decisões que reflete no espaço publico, pois contribui para a construção de um meio socialmente justo e sustentável.

Ao analisar a produção atual da Oficina de Vidro, é notória uma tendência do grupo em criar formas irregulares e orgânicas, que poderiam ser mais bem aproveitadas em outras aplicações até então não exploradas. No primeiro contato com - Labsol, os participantes da oficina enumeraram algumas dificuldades encontradas ao se trabalhar com vidros no Brasil, como a disponibilidade de variedades em relação à textura e coloração, tornando então inviável importar esse material. Foi citado também o processo de tingimento do vidro, que tornava a cor mais opaca e que o verniz não promovia uma duração eficaz.

\subsection{Associação Cornélia Vlieg e o Armazém das Oficinas}

O Armazém das Oficinas é uma loja localizada em Campinas-SP que serve como marca dos produtos e serviços das oficinas desenvolvidos pelo NOT - Núcleo das Oficinas de Trabalho -, da Associação Cornélia Vlieg, que atua em conjunto com o Serviço de Saúde "Dr. Cândido Ferreira", sediado no distrito de Sousas, da mesma cidade. O Núcleo das Oficinas de Trabalho (NOT) atende indivíduos de baixa renda que 
apresentam quadros de doença mental, vulnerabilidade e que não recebem oportunidades de inserção no mercado formal. O NOT é constituído por 14 oficinas: Culinária Eventos, Culinária Nutrição, Papel Reciclado, Vitral, Construção Civil, Ladrilho Hidráulico, Agrícola, Mosaico, Marcenaria, Serralheria, Vela, Vitral Plano e Gráfica.

Criada em 2002, a loja Armazém das Oficinas tem como missão gerar renda para as pessoas com sofrimento mental, por meio da produção e comercialização de serviços e produtos artesanais que possam competir com o preço do mercado. Além da geração de renda, o objetivo também é resgatar a dignidade, a capacidade dos usuários de saúde mental, incluindo-os à sociedade. (Armazém das oficinas, 2016).

\subsection{Labsol + Associação Cornélia Vlieg e Núcleo das Oficinas de Trabalho}

A coordenação do NOT, em agosto de 2015, entrou em contato com o Labsol, apresentando oficinas bem estruturadas e com uma tradição de produtos artesanais. Foi solicitado ao laboratório assessoria para analise de algumas linhas de seus produtos, desenvolvimento de estratégias que unificassem a produção das diferentes oficinas a fim de criar uma identidade local e criação de eixos temáticos que contemplassem os itens produzidos pela associação, dando uma importância maior as oficinas de Papel Reciclado, Vitral, Ladrilho, Mosaico, Marcenaria, Serralheria, Vela, Vitral Plano e Gráfica. Assim, baseado pelos conceitos de Sustentabilidade, Ecodesign, Economia Solidária e pela metodologia de projeto de Baxter, o laboratório vem desenvolvendo o redesign das linhas de produção da associação.

\subsection{0 projeto de redesign da Oficina de Vitral}

A partir da demanda apresentada pela Associação Cornélia Vlieg, foi definido como objetivo atender as necessidades atuais do grupo, como desenvolver a linha de produtos da Oficina de Vitral e aprimorar o acabamento dos artefatos, visando agregar valor estético aos produtos, tornando-o mais atrativo ao mercado. Os conceitos escolhidos para a linha de produtos são embasados nas demandas da associação e podem ser divididos entre três elementos:

- Elementos figurativos

1. Plantas, pétalas, flores, natureza, animais, estações do ano.

- Elementos abstratos

1. Cheiro, diversidade, multiplicidade, genialidade, lembranças, infância, assimetria.

- Elementos construtivos

1. Luminária, moldura, móbile, padronagem.

Um das propostas do laboratório é desenvolver produtos de vidro como peças que envolvam luz, sem necessariamente depender do uso de uma vela ou lâmpada, ou seja, seriam artefatos decorativos que interagem com o sol, o que nomeamos de mensageiros solares, uma espécie de mensageiro-de-vento, mas modificados pela luz. O grupo apresenta experiência no desenvolvimento de luminárias que usam lâmpadas e velas e, por isso, propõe-se também a elaboração de novos formatos para esses objetos, focando em explorar formas irregulares e as espessuras das estruturas. Além disso, seria interessante para o grupo uma linha de objetos utilitários que usassem pedaços pequenos de vidros trabalhados de forma irregular, a fim desse material não 
ser desperdiçado devido ao seu tamanho. Essas peças podem ser confeccionadas utilizando massa epóxi, já utilizada pela oficina, e estruturas e/ou pequenas partes de ferro, que podem ser fabricadas pela Serralheria, além de correntes e outros elementos de ligação. Tudo isso, respeitando o Tripé do Labsol e a dinâmica de trabalho das oficinas da associação.

Maria Barber (Figura 2), artista britânica que confecciona pequenos artefatos de vidro e metal com formas de pássaros teve seu trabalho como grande inspiração para o projeto. Sua técnica foi utilizada como referência, adaptando-a ao cotidiano do trabalho da oficina, fazendo uso da estrutura de epóxi e inserindo elementos metálicos, como arame, a fim de resultar na produção de peças decorativas com temas como natureza e animais (Figuras 3 e 4). Levando em consideração a experiência do grupo na produção de luminárias, também propomos a confecção de novos formatos para esses produtos, inovando ao utilizar formas irregulares e a espessura das estruturas (Figura 5).

As peças decorativas em vidro com formas de animais de cores e texturas diversas podem ser dispostas sobre mesas ou aparadores ou até penduradas em série, de modo a balançarem ao sol, sozinhas ou em grupos diversos, unindo vários modelos de desenhos diferentes. A produção desses itens pode unir o trabalho realizado tanto da oficina de vitral, quanto da serralheria, pois pode ser desenvolvido utilizando a massa epóxi, material já manipulado pelo grupo, e com pequenas partes e estruturas de ferro que serviriam como sustentação.

Objetos utilitários que usassem pequenos pedaços de vidro também são uma proposta do Labsol, pois seriam elaborados a partir de formas irregulares, fazendo uso das mesmas bases que a oficina de vitral já é acostumada a trabalhar (Figura 5). Essas peças são construídas sobre bolas de isopor que não cobertas por inteiro, promovendo uma gama de possibilidades além da forma específica da esfera. Da mesma forma que os animais de casos de vidro, essas peças também seriam beneficiadas por estruturas feitas na Serralheria, ou até mesmo por bases circulares, para maior sustentação, fabricadas na marcenaria da Associação.

Além das peças novas, elaboramos algumas alternativas para os produtos já existentes, sugerindo diversas formas de acabamento usando materiais da Serralheria e Marcenaria (Figura 5), como bases de madeira maciça para os abajures com faces de vidro reto, com acabamento em quadrados de lata, como algumas peças da Serralheria. Essas bases podem ser retas, geométricas ou até um tronco de árvore sinuoso, cujas formas entram em contraste com as partes retas da parte superior, originando peças únicas. 


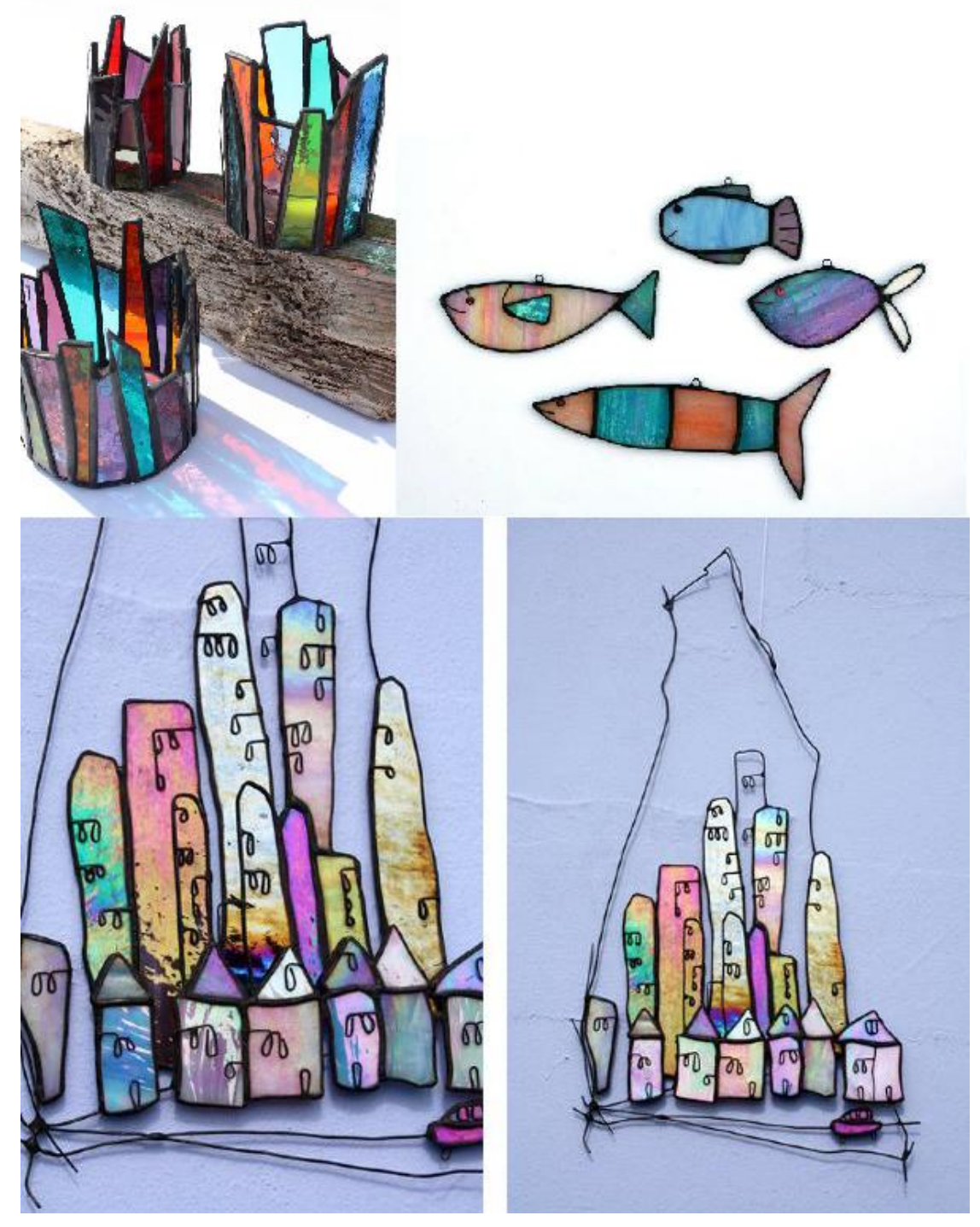

Figura 2 - Peças de Maria Barber Fonte: Acervo Labsol. 

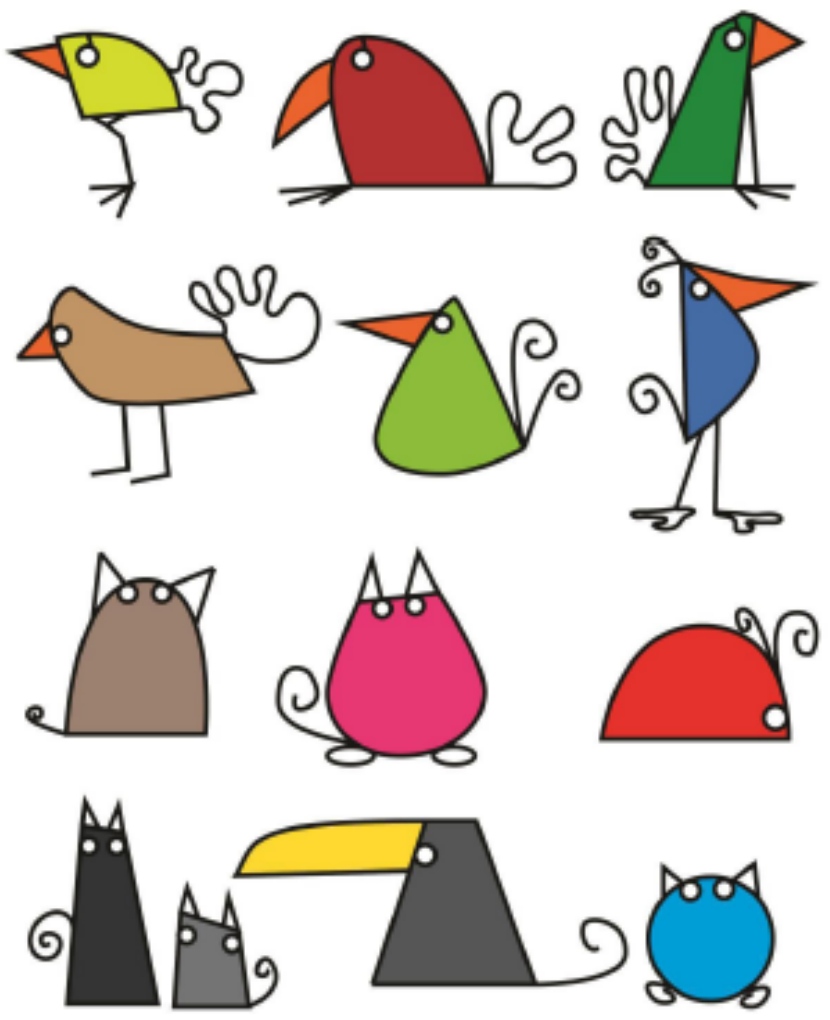

Figura 3 - Exemplos de animais que poderiam ser feitos com peças irregulares de vidro. Fonte: Acervo Labsol.
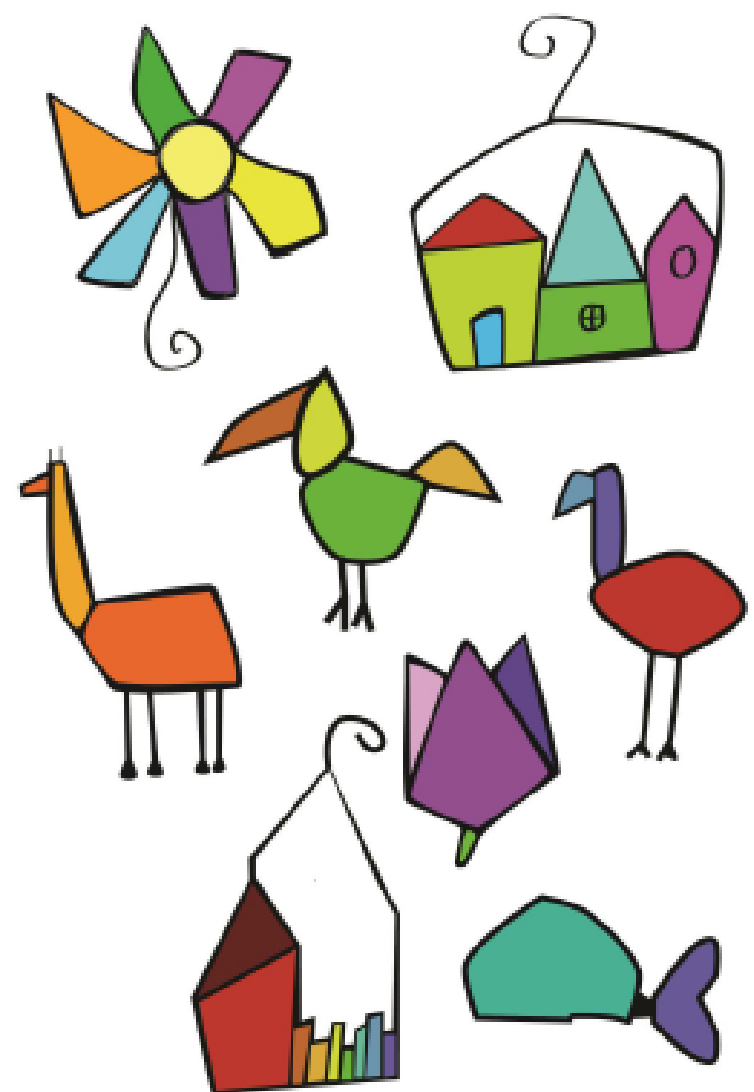

Figura 4 - Demais peças que podem ser confeccionadas com pedaços irregulares de vidro. Fonte: Acervo Labsol. 

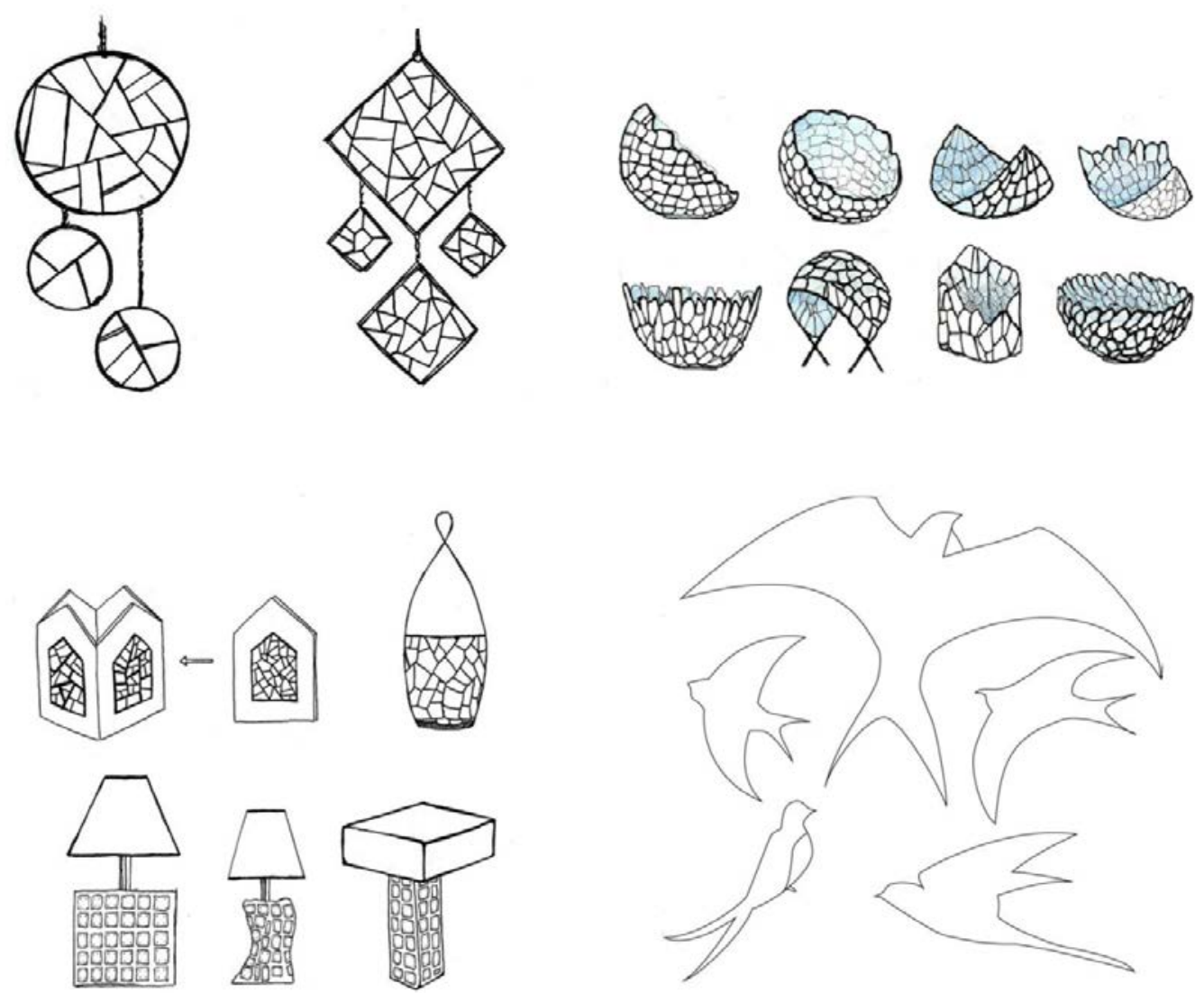

Figura 5: Da esquerda para a direita, de cima para baixo: Mensageiros solares com formas abstratas; peças utilitárias usando peças de vidro e massa epóxi (com bases de madeira ou metal);peças alternativas; andorinhas.

Fonte: Acervo Labsol.

\subsection{Metodologia de Projeto}

O desenvolvimento do projeto em andamento trata-se de um trabalho empírico de caráter prático, embasado em bibliografias que envolvam áreas como design, moda, pesquisa cultural e de mercado, química/ambiental, tendo como tripé conceitual a Sustentabilidade, o Ecodesign e a Economia Solidária, com aplicações da Metodologia do Projeto em Design do Produto (BAXTER, 2000), procurando atender as demandas da Associação Cornélia Vlieg e o desenvolvimento de novos produtos que agreguem valor a produção artesanal das oficinas, tendo em conta as questões socioculturais em que a associação está inserida. A metodologia de projeto em Design será utilizada na reformulação dos produtos já existentes e na criação de novos, adaptando métodos e processos de produção do vidro em parceria com as estruturas feitas pela Serralheria, aprimorando seu acabamento.

É importante manter todas as portas abertas para a geração de conceitos, desde que as mesmas sejam formuladas de maneiras realistas, dentro das possibilidades técnicas e econômicas da empresa (BAXTER, 2000, p. 176).

No sétimo capítulo (Projeto conceitual), Baxter destaca que o termo conceito faz parte do processo de criação de uma peça de design. Afirma que a geração de maior número possível de conceitos é o ideal para o sucesso de um projeto conceitual para que $o$ melhor seja selecionado, que é o caso da Oficina de Vitral, em que várias ideias foram dispostas e um eixo temático foi escolhido para a partir de então desenvolver uma 
nova linha de produtos.

Baxter propõe que o processo de desenvolvimento de produto tem como o objetivo necessita passar por etapas de observação de percepção do "problema", considerando os aspectos visuais, de fabricação e técnicas utilizadas, as demandas do mercado, preocupação ecológica e com o custo envolvido, além da satisfação do consumidor.

\section{CONCLUSÃO}

Após visitar a sede do Núcleo das Oficinas (NOT) e o Armazém das Oficinas para conhecer de perto sua produção, o Labsol entendeu melhor sobre os princípios operacionais, aspectos técnicos do grupo e dos materiais utilizados nas linhas de produção.

As propostas de redesign da linha de artefatos da Oficina de Vitral ainda não começaram a ser confeccionadas, mas receberam grande aceitação por parte do grupo. Como o projeto se encontra em andamento, estudos e testes ainda precisam ser realizados para identificar possíveis inviabilidades na execução das ideias apresentadas, além de novas possibilidades de parcerias com as outras oficinas além da Serralheria.

Projetamos para o futuro grandes melhorias na produção das peças e sua aceitação no mercado, atraindo cada vez mais o público-alvo. As ações do Labsol em parceria com a Associação Cornélia Vlieg buscam qualificar suas criações já existentes sugerindo novas possibilidades dentro da realidade do grupo, valorizando a aliança entre design e artesanato e aplicando conceitos de projeto e do tripé Sustentabilidade, Ecodesign e Economia Solidária.

\section{REFERÊNCIAS}

ASSOCIAÇÃO CORNÉLIA VLIEG, Quem Somos . 2016. Disponível na internet por http em:<http://www.armazemoficinas.com.br/site/quem-somos/42-associacao-corneliavlieg-.html>. Acesso em 15 mai. 2016.

BAXTER, Mike . Projeto de Produto. São Paulo: Blucher, 2000.

BORGES, Adélia. Design+Artesanato. São Paulo: Terceiro Nome, 2011.

GOYA, C. R.; ANDRADE, A. B. P.; DOMICIANO, C. L. C.; ROSSI, D. C.; MEDOLA; F. O.; HENRIQUES, F, SILVA, J. P. C., PASCHOARELLI, L. C.; MOURA, M.; RODRIGUES, O. V.; BIGAL, S. M.; BARATA, T. Carnaval, Cultura Popular e Design - Uma Experiência de Extensão Universitária em Design In: Ensaios em Design - Práticas Interdisciplinares.1 ed. Bauru: Canal 6 Editora, 2014, p. 136-156.

MANZINI, E.; VEZZOLI, C. O Desenvolvimento de Produtos Sustentáveis. São Paulo: USP. 2008.

MANZINI, Ezio; VEZZOLI, Carlo, trad. CARVALHO, Astrid de. O Desenvolvimento de Produtos Sustentáveis: os requisitos ambientais dos produtos industriais. São Paulo: EDUSP, 2002.

SINGER, Paul. Introdução à Economia Solidária. São Paulo: Fundação Perseu Abramo, 2002. 